\title{
E1 II Congreso de Venezuela. Conformación de un gobierno popular representativo, Angostura: 1818-1819*
}

\begin{abstract}
Ángel Rafael Almarza Villalobos
Profesor del Instituto de Investigaciones Históricas de la Universidad Michoacana de San Nicolás de Hidalgo (México). Correo electrónico: almarzavillalobos@gmail.com. El autor doctor en Historia de la Universidad Nacional Autónoma de México. Entre sus publicaciones recientes tenemos: en coautoría "La independencia de las Provincias Unidas en Sud-América vista desde Venezuela" en Prismas. Revista de Historia Intelectual No. 20 (2016) y "Representación política y prácticas electorales en los albores de la República de Colombia: el caso de la Provincia de Guayana, 1820-1821” en Claves. Revista de Historia No. 2 (2016). Entre sus temas de interés están historia política hispanoamericana de la primera mitad del siglo XIX.
\end{abstract}

Recibido: 9 de junio de 2016

Aprobado: 05 de agosto de 2016

Modificado: 18 de agosto de 2016

Artículo de investigación científica

DOI: http://dx.doi.org/10.15648/hc.32.2018.4

* $\quad$ Este artículo forma parte del proyecto: "El II Congreso de Venezuela. Conformación de un gobierno popular representativo, Angostura: 1818-1819" financiación propia.

Esta publicación está bajo una licencia Creative Commons Reconocimiento-NoComercial 4.0 
E1 II Congreso de Venezuela. Conformación de un gobierno popular representativo, Angostura: 1818-1819

\title{
Resumen
}

Las prácticas electorales representan una inestimable fuente para la comprensión de la cultura política en las experiencias representativas que se instauraron en Hispanoamérica finalizando la segunda década del siglo xix. En ese sentido, el objetivo del presente artículo consiste en estudiar, analizar y comprender los aspectos más significativos que en materia de legislación electoral se pusieron en práctica para el restablecimiento del gobierno representativo en Venezuela, con especial atención en las elecciones para el Congreso de Angostura de 1819. Experiencia, por demás, que sirvió de modelo para los comicios del Congreso General de Colombia de 1821; ambas prácticas convertirían al sistema representativo colombiano en un proyecto viable y duradero que cambió la manera de hacer política en Tierra Firme.

Palabras clave: representación política, prácticas electorales, gobierno representativo, elecciones, Venezuela, Nueva Granada.

II Congress of Venezuela. Formation of a representative popular government, Angostura: 1818-1819

\begin{abstract}
The electoral practices represent an inestimable source for the understanding of the political culture in the representative experiences that were established in Hispano-America at the end of the second decade of the 19th century. In this regard, the objective of this article is to study, analyze and understand the most significant aspects that, in terms of electoral legislation, were implemented to the restoration of representative government in Venezuela, with special attention to the elections for the Angostura Congress in 1819. Experience, otherwise, that served as a model for the elections of the General Congress of Colombia in 1821; both practices would convert the representative Colombian system into a viable and lasting project that changed the way of making policies in Tierra Firme.
\end{abstract}

Keywords: political representation, electoral practices, representative government, elections, Venezuela, Nueva Granada. 
O II congresso de Venezuela. Conformação de um governo popular representativo, Angostura: 1818-1819

\section{Resumo}

As práticas eleitorais representam uma inestimable fonte para o entendimento da cultura política nas experiências representativas que se instauraram em Hispanoamérica finalizando a segunda década do século XIX. Nesse sentido, o objectivo do presente artigo consiste em estudar, analisar e compreender os aspectos mais significativos que em matéria de legislação eleitoral se puseram em prática para a restauração do governo representativo em Venezuela, com especial atenção nas eleições para o congresso de Angostura de 1819. Experiência, por demais, que serviu de modelo para as eleições do Congresso Geral de Colômbia de 1821; ambas práticas converteriam ao sistema representativo colombiano num projecto viável e duradouro que mudou a maneira de fazer política em Terra Firme.

Palavras-chave: representação política, práticas eleitorais, governo representativo, eleições, Venezuela, Nova Granada

\section{IIème Congrès de Venezuela. Création d'un gouvernement populaire représen- tatif, Angostura 1818-1819}

\section{Résumé}

Les pratiques électorales représentent une source inestimable pour la compréhension de la culture politique des expériences représentatives qui ont été instaurées en Amérique Latine vers la fin de la seconde décennie du XIX siècle. Dans ce sens l'objectif de cet article est celui d'analyser et comprendre les aspects les plus significatifs, concernant la législation électoral, qui ont été mis en œuvre en vue du rétablissement du gouvernement représentatif au Venezuela. Un accent particulier sur les élections pour le congrès d'Angostura de 1819 est fait. Cette expérience par ailleurs, a servi comme modèle pour les élections du Congrès Général de Colombie en 1821; Ces deux pratiques transformeraient le système représentatif colombien dans un projet viable et durable qui a changé la manière de faire la politique sur la Terre Ferme.

Mots clés: représentation politique, pratique électorale, gouvernement représentatif, élections, Venezuela, Nueva Granada. 


\section{INTRODUCCIÓN}

Luego de un breve exilio en el Caribe, Simón Bolívar -acompañado de cercanos oficiales del Ejército Libertador como Santiago Mariño, Manuel Piar, José Francisco Bermúdez y Carlos Soublette por mencionar algunos-, desembarcó el 31 de diciembre de 1816 en la ciudad de Barcelona al oriente de Venezuela. Allí estableció su cuartel general con el propósito de iniciar una nueva etapa en la guerra de independencia denominada Campaña de Barcelona. Su plan original era conquistar la Provincia de Caracas, sin embargo, diversos inconvenientes de índole militar lo obligaron a enfocar sus esfuerzos en la ocupación de la Provincia de Guayana, la cual culminó a principios de agosto de 1817 con la toma de su capital Angostura. De esta manera, el territorio recién conquistado se convirtió en la base militar, política y económica del Ejército Libertador y progresivamente, asentó los cimientos institucionales de la República de Venezuela y posteriormente, de Colombia bajo la figura de un gobierno popular y representativo.

A finales de 1818 buena parte de la Capitanía General de Venezuela se encontraba bajo el control de las autoridades monárquicas; solo las provincias de Guayana, Margarita, Cumaná y una parte de las provincias de Barcelona y Barinas se encontraba bajo el control del Ejército Libertador. Fueron meses marcados por una intensa movilización y actividad militar que inició en las provincias venezolanas y que posteriormente se trasladó al territorio neogranadino. Parte de Tierra Firme se encontraba bajo dominio español, pero en comparación con los años previos, los patriotas se encontraban en su mejor momento.

En este contexto, el artículo tiene como objetivo estudiar, analizar y comprender los aspectos más significativos que en materia de legislación electoral se pusieron en práctica para el restablecimiento del gobierno representativo en Venezuela, con especial atención en la alocución, convocatoria, reglamento y elecciones para el Congreso de Angostura de 1819,

84 proceso eleccionario que sirvió de modelo para la normativa legal al Congreso General de Colombia de 1821. Ambas experiencias convirtieron al sistema representativo colombiano en un proyecto viable y duradero -si lo 
comparamos con experiencias previas-, donde la participación ciudadana por medio de la elección de sus diputados fue la bandera de su gobierno y su nueva manera de hacer política ${ }^{1}$.

De esta manera, el énfasis está en el análisis de las prácticas políticas en sus diversas dimensiones, considerando de manera particular los espacios vinculados con el proceso comicial y sus implicaciones en la dinámica política y social de los ciudadanos de la naciente República de Venezuela. Para alcanzar el objetivo fue necesaria la formulación de las siguientes interrogantes: ¿Cuál fue el contexto en el que se realizó la convocatoria, el reglamento y el proceso comicial? ¿Por qué el sufragio fue considerado como el mecanismo idóneo para la selección de los diputados? ¿Cómo se desarrollaron las elecciones en las diferentes provincias? Estas y otras incógnitas me ayudaron a entender la trascendencia que adquirió para la vida política de los venezolanos la convocatoria, reglamento y elección de diputados del Congreso de Angostura.

Por varias razones las prácticas electorales de estos territorios representan una valiosa fuente para el estudio, análisis y comprensión de la cultura política en los inicios del establecimiento del gobierno representativo. La primera está relacionada con el tema de la movilización ciudadana antes, durante y después de las jornadas comiciales, lo cual evidencia una marcada e interesante politización de la sociedad debido a la novedad, significado y alcance del asunto y por la participación de la ciudadanía en el mismo acto electoral. La segunda razón tiene que ver con el poder que adquirió el voto como mecanismo idóneo de legitimación del régimen representativo, en este caso venezolano, y como instrumento para acercar a la ciudadanía

1 El presente trabajo forma parte de una investigación de mayor aliento que desarrollé en mi tesis de Doctorado en Historia titulada: Los inicios del gobierno representativo en la República de Colombia. México, Universidad Nacional Autónoma de México, 2015, 447 pp. Conté con la valiosa asesoría del Dr. Alfredo Ávila como tutor principal, así como de la Dra. Virginia Guedea y el Dr. José María Portillo Valdés como miembros del comité tutor. El Consejo Nacional de Ciencia y Tecnología (CONACYT) me apoyó con una beca para realizar mis estudios doctorales. En la actualidad sigo desarrollando esta línea de investigación con el proyecto: Representación política y prácticas electorales. El caso de Colombia y el Río de la Plata, 1819-1823, bajo el auspicio del Consejo de la Investigación Científica de la Universidad Michoacana de San Nicolás de Hidalgo desde el año 2015 hasta el 2017. Agradezco los acertados comentarios, críticas y recomendaciones realizados por mi colega Rosángel Vargas en este trabajo de investigación. 
en la toma de decisiones políticas. Finalmente, una tercera razón radica en el hecho de que la movilización ciudadana, la participación política y el ejercicio del voto transformaron progresivamente las relaciones de poder, dando sentido a dinámicas y prácticas enmarcadas en el sistema representativo de principios de la década de 1820.

No obstante, es importante señalar que el principio y la práctica de la representación política como factor de legitimación política ${ }^{2}$ no fue una novedad exclusiva en Tierra Firme, ya que desde 1808 cuando se produce el colapso de la monarquía española como consecuencia de las abdicaciones de Bayona y la invasión francesa, el debate en torno a la representación fue un aspecto clave del complejo proceso que culminó con la formación de nuevos estados nacionales bajo el amparo de un sistema representativo. Desde el Imperio Mexicano hasta las Provincias Unidas del Río de la Plata, ${ }^{3}$ este debate no perdió vigencia a pesar de tener más de una década como materia de discusión y es que la necesidad de reemplazar la cuestionada legitimidad de la monarquía española abrió el camino al establecimiento de un régimen representativo sobre cuyas bases debía asentarse la nueva legitimidad política. La idea era establecer un régimen de elección indirecta para ordenar, controlar y disciplinar la participación de la sociedad tanto civil como militar, de esta manera la representatividad política garantizaría la legitimidad y gobernabilidad del sistema.

\section{1. ...ACELEREN LA MARCHA de LA RESTAURACión DE NUESTRAS INSTITUCIONES REPUBLICANAS...}

La primera versión del proyecto de convocatoria para el Congreso de Ve-

2 Sobre la práctica del principio de representación como fundamento de la legitimidad política es fundamental los aportes realizados por Hanna Fenichel Pitkin, El concepto de representación (Madrid: Centro de Estudios Constitucionales, 1985); y Bernard Manin, Los principios del gobierno representativo (Madrid: Alianza Editorial, 1998).

3 Entre los mejores trabajos puedo destacar: Antonio Annino (coord.), Historia de las elecciones en Iberoamérica, siglo XIX. De la formación del espacio político nacional (México: Fondo de Cultura Económica, 1955); Alfredo Ávila, En nombre de la nación: la formación del gobierno representativo en México (México: Universidad Nacional Autónoma de México, 2005); y Marcela Ternavasio, La revolución del voto. Política y elecciones en Buenos Aires, 1810-1852 (Buenos Aires: Siglo XXI, 2002). 
nezuela fue redactada el $1^{\circ}$ de octubre de 1818 , mismo día de la creación de la comisión nombrada para tal fin. El texto fue examinado dos semanas más tarde para su aprobación y posterior publicación el 24 de octubre de 1818 en el único medio oficial patriota que existía en Angostura: el Correo del Orinoco ${ }^{4}$. En esa reunión Simón Bolívar propuso a los miembros de la Comisión la redacción de la Convocatoria y el reglamento para la elección de diputados que conformarían el Congreso Nacional. En su alocución consideró que las circunstancias de la guerra favorecían al Ejército Libertador y en consecuencia -y es precisamente el punto más importante de su arenga-, era el momento oportuno para la constitución de un cuerpo representativo que permitiría "ser libres bajo los auspicios liberales", es decir, derivados de la voluntad popular base del sistema representativo ${ }^{5}$.

El historiador neogranadino José Manuel Restrepo señaló que la convocatoria surgió a partir de un acuerdo entre las fuerzas políticas y militares, quienes habían manifestado "con mayor energía sus deseos de que se reorganizara el gobierno supremo de la república. [...] deseaban que se le pusiera algún freno, y que se estableciera por lo menos una sombra de representación popular" ". Clément Thibaud afirmó que esta apropiación de la "Patria o de la Nación por el Ejército" se presenta en este contexto de conflictividad entre el poder civil y militar; se trata de limitar la provisionalidad del Consejo de Estado al nombrar una representación popular? Más allá de estas miradas, estoy convencido que la legislación electoral no fue una imposición de Bolívar o sus oficiales más allegados, sino consecuencia de intensas negociaciones políticas entre los grupos sin descartar las experiencias representativas previas, tales como los primeros procesos electorales iniciados en 1809 para la elección de diputados a la Junta Su-

4 Véase al respecto: Inés Quintero y Ángel Rafael Almarza V., "Una segunda oportunidad. Representación y revolución en la República de Colombia: 1819-1830”, en Las revoluciones en el largo XIX latinoamericano, eds. Rogelio Altez y Manuel Chust (Madrid: Iberoamericana/Vervuert, Estudios AHILA de Historia Latinoamericana, 12, 2015), 109-130.

5 "Sesión del Consejo de Estado del $1^{\circ}$ de octubre", Correo del Orinoco, Angostura, no 12, 10 de octubre de 1818.

6 José Manuel Restrepo, Historia de la revolución de la República de Colombia en la América Meridional (Medellín: Editorial Universidad de Antioquia, 2009), v. 1, 973.

7 Clément Thibaud, República en armas. Los ejércitos bolivarianos en la guerra de independencia en Colombia y Venezuela (Bogotá: Instituto Francés de Estudios Andinos y Editorial Planeta, 2003), 400 . 
prema Central y Gubernativa de España e Indias, las realizadas durante el doceañismo gaditano y la experiencia electoral insurgente venezolana de 1810-1812.

La búsqueda de bases legales viables para apoyar el proyecto republicano implicó diversas disputas entre los partidarios de la independencia hasta que Bolívar con la convocatoria al Congreso de Angostura de 1819, logró definir su liderazgo político respondiendo a las exigencias de los diferentes sectores de la sociedad comprometidos con el restablecimiento del orden republicano en Venezuela. A pesar del control patriota del margen sur del río Orinoco, la Provincia de Caracas y una parte considerable de la Capitanía General de Venezuela permanecieron leales a la monarquía española sin sufrir percances como consecuencia de la guerra de independencia. En este sentido, existieron dos bandos claramente definidos que se atribuyeron la legitimidad representativa; sus diferencias no solo se plantearon en los escenarios bélicos, sino también en una permanente propaganda a través de la prensa.

Como veremos en las siguientes páginas, el reglamento electoral redactado bajo la dirección de Juan Germán Roscio fue concebido por los actores políticos más representativos e influyentes del gobierno patriota, quienes seleccionaron las reglas y procedimientos más idóneos a las circunstancias con el objeto de que sus resultados fuesen satisfactorios con sus intereses. Es importante recalcar que tanto las experiencias electorales anteriores, como la implementación de elementos de otros modelos comiciales fueron fundamentales en el reglamento electoral de 1818, aspectos que incorporé brevemente en el desarrollo del presente artículo. Asimismo, es necesario advertir que aunque los criterios ciudadanos no experimentaron cambios significativos en comparación con experiencias representativas anteriores, la situación de guerra y la urgencia de la convocatoria determinaron que la estructura y organización del proceso electoral sí sufrieran modificaciones. Estos cambios se evidenciaron en los lugares donde se ejerció el derecho a voto, en la división territorial y en la idea misma de representación política.

88 En este sentido, otra particularidad de la legislación electoral fue el análisis de las condiciones del derecho a voto, el cual evidencia que a pesar de las reservas se otorgó la ciudadanía a individuos que en otras circunstancias 
no habrían estado contemplados. El precario control territorial, la inestabilidad de la República, aunado al descenso de la población ocasionados por casi una década de guerra, así como la presión de sectores de la sociedad, obligaron a reducir las restricciones para lograr así una mayor participación de la población en el establecimiento del gobierno representativo. El ejemplo más claro fue el voto militar ${ }^{8}$.

La comisión consideró que para otorgar el derecho al sufragio a los miembros del Ejército Libertador se debía cumplir con una distinción adicional: ser oficial. De esta manera, pertenecer a la jerarquía militar era equivalente al ejercicio de un arte militar o mecánico, o la condición censitaria para los civiles ${ }^{9}$. En cualquiera de los casos, lo importante era conseguir los mejores representantes entre los hombres que formaban parte de la población venezolana.

Más allá de las particularidades del proceso eleccionario, ¿por qué consideraron las autoridades de Angostura el sufragio como el mecanismo idóneo para la selección de los diputados que integrarían el segundo Congreso de Venezuela? En líneas generales las razones fueron dos: la primera, porque estaban convencidos de que el origen de toda legitimidad política se fundamentaba en la voluntad popular -o en sus diferentes acepciones-; y segundo, porque la elección según la concepción de los gobiernos representativos de la época siempre eleva a los mejores a los cargos públicos.

\section{Alocución y CONVOCATORIA A LOS PUEBLOS DE VENEZUELA}

El 22 de octubre de 1818 Simón Bolívar convocó al segundo Congreso

8 Véronique Hébrard destacó que la idea de ciudadanía activa y pasiva que fue empleada por Bolívar en su discurso al Congreso de Angostura, solo se adoptó por motivos vinculados al utilitarismo. Véronique Hébrard, "¿Patricio o soldado: qué «uniforme» para el ciudadano? El hombre en armas en la construcción de la Nación (Venezuela, $1^{\text {ta }}$ mitad del siglo XIX)”, Revista de Indias, $n^{\circ} 225$, mayo-agosto (2002): 441.

9 Asegura Véronique Hébrard que es precisamente en el marco de la redefinición de los cuadros institucionales en una guerra que lleva cerca de una década, que el militar se convierte en uno de los elementos fundamentales en materia de ciudadanía, y a pesar de que el reglamento de 1818 y la Constitución de 1819 lo consideran, no lo favorecerán de manera explícita. "¿Patricio o soldado: qué «uniforme»...", 441. 
de Venezuela por medio de una proclama titulada A los pueblos de Venezuela, el cual tendría la responsabilidad de "Fijar la suerte de la República combatida y errante", y solo con ella "nuestras heridas van a curarse al abrigo de una representación legítima"10. Para Bolívar, la situación de la guerra de independencia había cambiado a favor del Ejército Libertador, por esa razón en su comunicación destacó que al lograr la liberación de Guayana "Nada nos impide devolver al pueblo sus derechos soberanos". El llamado fue claro: "Elegid por magistrados a los más virtuosos de vuestros conciudadanos y olvidad, si podéis, en vuestras elecciones a los que os han librado" $"$.

Por su parte, la alocución que antecedió al reglamento electoral fue una disertación contra la monarquía católica en defensa de la independencia y la libertad; además, ofreció una síntesis sobre el proceso emancipador desde 1810 donde destacó los aciertos y errores cometidos durante las experiencias republicanas anteriores y las intenciones fallidas por establecer un gobierno representativo en Tierra Firme. Los redactores de la arenga consideraron que la libertad civil que tanto anhelaba la República solo se podía fundamentar en el consentimiento general del pueblo ${ }^{12}$. Destacaron igualmente la solicitud de Bolívar para conformar una comisión especial para la

10 Simón Bolívar, "A los pueblos de Venezuela", Correo del Orinoco, Angostura, n 14, 24 de octubre de 1818.

11 Simón Bolívar, "A los pueblos de Venezuela", Correo del Orinoco, Angostura, n 14, 24 de octubre de 1818. Por su parte, Clément Thibaud consideró que el discurso de Bolívar evidenció la complejidad de la situación, ya que se deseaba que los militares se dedicaran a las actividades de la guerra, y los civiles al establecimiento de la República, pero ¿sobre qué base popular podría garantizar la consulta electoral? La organización misma del proceso comicial evidenció "la teoría del ejército como vanguardia de la nación a punto de nacer”. Evidentemente la convocatoria a un congreso respondió a una necesidad política y militar. República en armas..., 401-402. No tengo la menor duda de que el Ejército Libertador fue fundamental para establecer los cimientos de Venezuela y luego del proyecto colombiano pero, como veremos en este y en otros trabajos de mi autoría, la participación ciudadana de la población civil fue igual de importante para lograr el establecimiento efectivo y exitoso del gobierno representativo en Tierra Firme durante la experiencia colombiana de la década de 1820 y los posteriores como entidades independientes.

12 "Reglamento para la segunda convocatoria del Congreso de Venezuela", Correo del Orinoco, Angostura, no 14, 24 de octubre de 1818. Se terminó de insertar en la edición no 15 del 21 de noviembre de ese mismo año. La misma, además de su publicación en la prensa oficial, fue remitida a los comandantes de las provincias libres de Venezuela, al de la Provincia de Casanare y al gobernador del obispado de Guayana para su ejecución. En ese momento, su difusión por los diferentes medios posibles era fundamental para el éxito de la jornada comicial. 
redacción del "proyecto convocatorio de la representación nacional” y las diferentes oportunidades que había intentado convocar el congreso: "fue una de las principales miras del general en jefe: su proclama de mayo de 1816 en Margarita, lo declara expresamente"13.

Sobre las características de la convocatoria advirtieron que a diferencia de la experiencia representativa de 1810, este reglamento tendría modificaciones por las condiciones particulares en las que se encontraba parte del territorio venezolano consecuencia de la guerra de independencia. Uno de los inconvenientes era la falta de un censo civil reciente y realizarlo era imposible por las espinosas circunstancias que nos rodean, además sería cosa ardua y dilatada, por ello la solución que proporcionó la comisión fue "simplificar la elección, aproximándola a su estado primitivo", es decir, al nombramiento de representantes por medio de votaciones directas ${ }^{14}$.

Se seleccionarían 30 diputados provinciales entre las divisiones militares y las parroquias libres, pero ninguno de los representantes "ha de ceñir sus ideas ni su representación al distrito de su nombramiento ni a cualquiera otro en particular sino generalmente a todas y cada una de las porciones de Venezuela", evidencia de la transformación de la concepción de la representación y su aplicación en la dinámica política. Se les solicitó expresamente a los diputados electos unidad e indivisibilidad y la importancia de desprenderse del espiritu de provincia y considerarse "representantes de todos y cada uno de los distritos de Venezuela"15.

La comunicación concluyó con un llamado general a los americanos a unirse a la causa de Venezuela ya que en su opinión, los diputados promoverían "el bienestar de toda la América insurrecta contra el poder arbitrario de la España”. La invitación puso énfasis en el territorio venezolano, pero amplió la convocatoria a la provincia neogranadina de Casanare para "consultar [a] aquel departamento la emancipación y libertad de la Nueva Granada, en que tienen los venezolanos contraídos una obligación espe-

13 "Reglamento para la segunda...", Correo del Orinoco, Angostura, no 14, 24 de octubre de 1818.

14 "Reglamento para la segunda...", Correo del Orinoco, Angostura, n 14, 24 de octubre de 1818.

15 "Reglamento para la segunda...", Correo del Orinoco, Angostura, no 14, 24 de octubre de 1818. 
cial" además de estar "concertado el plan de una incorporación que formase de los dos Estados en uno solo"16.

La intención de la conformación de la República de Colombia se evidenció en la misma alocución, ya que manifestó de manera explícita la necesidad del restablecimiento de un gobierno representativo a través de la convocatoria a los pueblos venezolano y neogranadino mediante un proceso electoral para nombramiento de diputados provinciales. De esta manera, el interés más importante era asentar las bases de un sistema representativo para preservar así la independencia y libertad de la república que se quería instaurar.

\section{Reglamento Electoral de 1818}

Como adelanté, la legislación que normaría el proceso electoral para el segundo Congreso de Venezuela evidenció importantes modificaciones en sus bases y organización con respecto a experiencias representativas anteriores, básicamente por las circunstancias generadas por la guerra de independencia; aunado a ello, la práctica adquirida en los procesos eleccionarios previos tanto republicanos como monárquicos, marcó significativamente esta normativa legal. Pero más allá de estos cambios, lo más revelador es que estableció de manera explícita que el pueblo es el soberano; no obstante, este delega su ejercicio a través del sufragio. Es importante destacar que los diputados electos gozaron de independencia y ejercieron sus cargos mediando entre la responsabilidad con sus electores y la objetividad al momento de la toma de decisiones.

El proceso electoral se realizó en dos espacios: el primero, en las instalaciones militares de las provincias venezolanas que permanecían en una situación extraordinaria como consecuencia de la guerra de independencia; y el segundo, en las parroquias venezolanas y neogranadinas que no se encontraban afectadas por el conflicto armado. La realización de los comicios en espacios públicos entusiasmó a la ciudadanía, lo que se evidenció en la movilización de la población legitimando el sistema representativo.

\footnotetext{
16 "Reglamento para la segunda...", Correo del Orinoco, Angostura, no 14, 24 de octubre de 1818.
} 
En el primer caso, el jefe de la división militar fue el encargado de su organización: convocar a los electores, certificarlos como idóneos, elaborar las listas de los ciudadanos y recolectar los votos ${ }^{17}$. Sobre este particular, quiero destacar los inconvenientes que podía significar la potestad que el reglamento otorgó a los oficiales de alto rango del Ejército Libertador, tanto en la calificación de los sufragantes como en la elección de los candidatos: en primer lugar, al tratarse de una fuerza castrense la coerción del voto seguramente fue una práctica común; en segundo lugar, como las votaciones no eran secretas y se realizaban por medio de papeletas con una población mayoritariamente analfabeta, al dictar sus candidatos en público evidencia lo limitado de las libertades ciudadanas al momento de ejercer su derecho al sufragio. No dudo que estos inconvenientes también se dieran en el espacio civil, aunque no de manera tan marcada.

Adicionalmente a la organización de las elecciones, la máxima autoridad militar debía orientar a los ciudadanos en sus deberes con el propósito de "prepararlos al mejor acierto de ella" y así dejar claro que cada uno de ellos "ha de estar bien advertido que viene a elegir por sí mismo, y no por medio de otros electores". El votante era también advertido que del "acierto, o desacierto en la elección depende la dicha o desdicha del país, y que la diputación, cualquiera que sea el lugar y cuerpo de donde ella resulte, no es para ninguno en particular, sino para toda la extensión en Venezuela". Para algún inconveniente mayor se nombraría una congregación de cuatro electores de los más recomendables e imparciales ${ }^{18}$.

En el caso de las parroquias pertenecientes a las provincias libres, el proceso electoral se desarrolló bajo la coordinación de las autoridades civiles y eclesiásticas, ambos controladores de diversos aspectos de la cotidianidad de los habitantes donde ejercían su jurisdicción y entes con la capacidad de convocar y organizar una actividad de estas características. Según la legislación, eran los encargados de divulgar a los candidatos, convocar a elecciones, definir quiénes estaban habilitados para votar y validar la elec-

17 "Reglamento para la segunda...", Correo del Orinoco, Angostura, no 14, 24 de octubre de 1818 y n 15, 21 de noviembre de 1818.

18 "Reglamento para la segunda...", Correo del Orinoco, Angostura, no 14, 24 de octubre de 1818 y n 15, 21 de noviembre de 1818 . 
ción. Seguramente también se contó con la participación de militares para resguardar el orden durante la realización de los comicios.

Tanto en las divisiones militares como en las parroquias libres, los electores eran convocados por medio de carteles, papeletas y emisarios, se verificaban los escrutinios mediante la comparación y cotejo de votos y eran seleccionados a los representantes por mayoría simple. En el caso de empate entre candidatos, el comisionado político o militar y la congregación electoral ampliada buscaba los mecanismos necesarios para solventar esa situación, "entendiendo que para esta elección decisiva podrá atenderse a cualquier especie de mayoría" "19; en este sentido, y en comparación con otros procesos eleccionarios, se eliminó el sorteo como mecanismo de selección en casos de empate, aunque era reconocido en procesos previos como una herramienta eficaz que buscaba evitar la organización de partidos, campañas electorales y variados procedimientos de votación, además de incorporar a la providencia en la elección.

Al concluir las elecciones, el comisionado remitía al jefe de la provincia o división los documentos relativos a los comicios, y aunque no existió uniformidad en la estructura y contenido de las actas y registros electorales del proceso de 1818-1819, el simple hecho de que fuera un requisito expresa la importancia de la formalización de la elección y su legitimidad ante la comunidad, pero también la posibilidad de que progresivamente la ciudadanía se familiarizara con la práctica electoral republicana.

En resumen, se elegirían por votación directa y no secreta a 30 diputados, cuya elección se distribuiría entre las divisiones militares de cada provincia -Caracas, Barcelona, Cumaná y Barinas-y las parroquias de las provincias libres -Guayana y Margarita-, a saber, cinco representantes por cada una. En la convocatoria se invitó a participar a las provincias venezolanas de Mérida y Trujillo aunque se encontraban en ese momento bajo la administración de las autoridades monárquicas de Caracas y también se invitó a "las demás provincias de la Nueva Granada que quieran imitar la conduc-

19 "Reglamento para la segunda...", Correo del Orinoco, Angostura, n 14, 24 de octubre de 1818 y n ${ }^{\circ}$ 15, 21 de noviembre de 1818. 
ta de Casanare, cuando tengan libertad de votar". ${ }^{20}$ Aunque no se puede simplificar el proyecto colombiano a un asunto estrictamente electoral, esta integración es una de las bases de la unión de la Nueva Granada y Venezuela consolidada el 17 de diciembre de 1819 en la Ley Fundamental de la República de Colombia. En este contexto, más allá de designar a los representantes del pueblo, se trataba de legitimar el gobierno y darle territorialidad a la joven república.

El derecho a participar estaba limitado a un sector de la población, el cual debía cumplir ciertos requisitos: ciudadanos venezolanos, de sexo masculino, mayores de 21 años si eran solteros o menores si eran casados, dueños de alguna propiedad de bienes raíces - no importaba si se encontraba en manos de las autoridades españolas- o ejercer una ciencia, arte liberal o mecánica ${ }^{21}$ o en su defecto, poseer tierras agrícolas o pecuarias o ser comerciante con un ingreso superior a los 300 pesos anuales. Estaba igualmente contemplada la participación de los empleados civiles y militares con ingresos superiores a 200 pesos anuales, una cantidad considerable para los estándares de la época. En el caso de los venezolanos o extranjeros en servicio militar, la reglamentación electoral no consideró la participación de toda la tropa, sino solo la de aquellos que cumplieran con los requisitos antes reseñados. En cambio, los oficiales y suboficiales del Ejército Libertador, así como los veteranos inválidos de la guerra sí gozaron del derecho al sufragio ${ }^{22}$.

En síntesis, la convocatoria para la elección de diputados al segundo congreso de Venezuela mantuvo su condición de sufragio censitario o restringido, basado en la dotación del derecho a voto solo a un sector de la población

20 "Reglamento para la segunda...", Correo del Orinoco, Angostura, no 14, 24 de octubre de 1818 y n ${ }^{\circ}$ 15, 21 de noviembre de 1818.

21 La idea medieval de arte liberal hace referencia a los estudios que tenían como propósito ofrecer conocimientos generales y destrezas intelectuales. Por su parte, se denominó arte mecánico a los producidos mediante procedimientos manuales en función de su utilidad para la sociedad.

22 "Reglamento para la segunda...", Correo del Orinoco, Angostura, n 14, 24 de octubre de 1818 y n 15, 21 de noviembre de 1818. Estaban excluidos los dementes, sordomudos, quebrados, deudores, vagos, desertores, "los procesados con causa criminal abierta y de gravedad", los que cometieran delitos electorales como la compra o venta del voto, y "los casados que sin razón legal vivan separados de sus mujeres". 
que cumpliera con características precisas. Estas limitaciones ligadas directa o indirectamente a las condiciones económicas o sociales del individuo, existentes en el ejercicio del voto desde el reglamento de 1810 o en la Constitución Federal venezolana de 1811, fueron ampliadas y condicionadas para que además pudieran participar los militares en el proceso electoral de 1818. Es importante recalcar que el voto censitario buscaba consolidar la idea del ciudadano ilustrado e independiente en un contexto republicano y liberal.

Sobre el tema del voto militar en las elecciones para el Congreso de Angostura de 1819 y otras experiencias futuras en la República de Colombia, la historiografía reciente lo interpretó de manera que podría ser debatido a la luz de la vinculación política, militar y social que experimentó la región en el contexto de la guerra de independencia y en el intento por establecer de manera definitiva un gobierno popular y representativo garante del orden político y social de la nueva república. Por ejemplo, David Bushnell en su artículo "La evolución del derecho de sufragio en Venezuela", consideró este nuevo escenario político como "populismo primordialmente militar" "23. Por su parte, Véronique Hébrard en su trabajo "Ciudadanía y participación política en Venezuela, 1810-1830”, consideró que fue una situación en la cual "la conducta como soldado determinaba la conversión, incluso la adquisición del título de ciudadano [...] la legalización del soldado-ciudadano" "24. Mientras que en "República en armas"..., Clément Thibaud es de la idea que con el voto de 1818 "los republicanos terminaron con una representación trunca. Deseaban reducir el poder de los militares en el aparato gubernamental, y se aprestaban, dadas las condiciones de organización del escrutinio, a fundar el poder civil en el voto de los militares mismos" 25 .

23 David Bushnell, "La evolución del derecho de sufragio en Venezuela", Boletín Histórico, n 29, mayo (1972): 195.

24 Véronique Hébrard, “Ciudadanía y participación política en Venezuela, 1810-1830”, en Independence and Revolution in Spanish America: Perspectives and Problems, eds. Anthony McFarlane y Eduardo Posada Carbó (Londres: University of London e Institute of Latin American Studies, 1999), 137 y 122-153.

25 Clément Thibaud, República en armas..., 401. Unos años más tarde, el autor es más tajante: "El intento de reinstitucionalización de la república mediante la elección del Congreso de Angostura en 1818, lejos de contrariar el avance del cesarismo, lo ratificó: los soldados eligieron a los diputados. 
A pesar del peso que la historiografía quiere darle al tema del voto militar en los inicios del establecimiento del gobierno representativo en Tierra Firme, en la búsqueda de elementos de subordinación de lo civil a lo militar en el orden político, valdría la pena reflexionar sobre los siguientes planteamientos y así considerar otra visión o interpretación sobre este tema. ${ }^{26}$ En primer lugar, se debería entender que las disposiciones y medidas tomadas por el gobierno republicano que consideró el voto de los venezolanos y extranjeros al servicio de las armas, respondió a un intento de acondicionamiento de la legitimidad política de la república, a las condiciones extraordinarias derivadas de casi una década de guerra de independencia, sin menospreciar la experiencia adquirida en procesos electorales previos, tanto realistas como insurgentes.

En segundo lugar, para esos años la organización republicana estaba amparada por un ejército en permanente campaña, por tanto, lo más lógico era considerar el voto castrense, aunque fuese restringido a una parte del sector: oficiales y suboficiales, quienes podrían representar en todo caso una cuarta parte del Ejército Libertador. Es por esta razón que más allá de interpretar esta decisión como populista, se trató más bien de una medida pragmática que intentó con éxito la vinculación del sector militar con la construcción institucional donde el señalado soldado-ciudadano no se equiparó en términos jurídicos al ciudadano-soldado, ya que la primacía seguía siendo de este último al estar el primero determinado jerárquicamente en la estructura militar en condición de subordinación.

El tercer elemento a considerar es que para la época en estudio, la distinción entre el militar y el civil no era tan marcada como se puede entender

El Ejército se convirtió en la fuente del poder constituyente; seguiría siéndolo por mucho tiempo, hasta el desmoronamiento de la Gran Colombia". Clément Thibaud, "Formas de guerra y mutación del ejército durante la guerra de la independencia en Colombia y Venezuela", en Revolución, independencia y las nuevas naciones de América, coord. Jaime E. Rodríguez O. (Madrid: Fundación MAPFRE Tavera, 2005), 358.

26 Algunas de estas ideas fueron sugeridas en el trabajo del Domingo Irwin G., "El voto militar en Venezuela: una visión histórica de conjunto", Latin American Studies Association (2004): s/p. Otro trabajo que se acerca al tema: Germán Guía, "El voto militar de 1819: instituido durante las vicisitudes de la guerra de independencia", CONHISREMI, Revista Universitaria de Investigación y Diálogo Académico, vol. 4, n 1 (2008): s/p. 
en tiempos recientes, ya que las condiciones de la guerra obligaron a la población sin formación militar a tomar partido en el conflicto armado, llegando muchos de ellos a importantes posiciones en la estructura militar patriota y realista. También valdría la pena recordar que para las elecciones de 1810 para el congreso de Venezuela, no se reglamentó la participación de los militares y a pesar de esto ocho oficiales del Ejército fueron electos diputados.

Para poder optar a ser diputado se requería ser ciudadano venezolano y en el caso de los extranjeros debían demostrar una residencia de al menos cinco años en el territorio, en ambos casos, debían ser mayores de 25 años, propietarios, habitantes de la provincia que querían representar y poseer un patriotismo a toda prueba, es decir, la no adhesión a ningún partido porque él "solo aspira al bien general, solo ejecuta la voluntad de la Nación y nunca puede considerarse partido a la Nación"27. Para el momento, el término patriotismo estaba vinculado a un elemento de unificación ciudadana en la búsqueda de un fin común, tal como lo define un breve artículo que se publicó en la Gazeta de Caracas del 17 de agosto de 1810: "el amor a la Patria es el motivo más poderoso para mover la voluntad de los ciudadanos"28. Esta condición también habla sobre la situación revolucionaria en el contexto de la guerra de independencia al reclamar una condición tan imprecisa como su adhesión a la justa causa de América. Además, se esperaba que el diputado electo gozara de independencia y "no somete su juicio a otro hombre, ni corporación [...]; porque está dotado como los otros de las facultades de pensar, y guiado solo de lo que notoriamente propende a la salud pública"29.

Para profundizar sobre las características que debía cumplir el representante electo, es conveniente preguntarnos: ¿A qué se refieren cuando se invitó a elegid a los más virtuosos? ¿Por qué solo los propietarios, comerciantes o hacendados, así como los empleados civiles y militares o quienes dominaran algún oficio, podían ejercer el derecho al voto? ¿Obedeció esta

27 "Reglamento para la segunda...", Correo del Orinoco, Angostura, no 14, 24 de octubre de 1818 y n ${ }^{\circ}$ 15, 21 de noviembre de 1818.

28 Gazeta de Caracas, Caracas, no 113, 17 de agosto de 1810.

29 "Diferencia entre el demagogo y el patriota", Correo del Orinoco, Angostura, no 67, 17 de junio de $1820 \mathrm{y} \mathrm{n}^{\circ} 68,24$ de junio de 1820 . 
decisión exclusivamente a las condiciones extraordinarias de la guerra de independencia o existía una tradición republicana que brindaba experiencias y referencias que fueron retomadas para la convocatoria al segundo Congreso de Venezuela de 1818 ?

Una de las principales características de los inicios de los gobiernos representativos -y ahí se inscribe la experiencia de Nueva Granada y Venezuela, y posteriormente la República de Colombia, al igual que otros casos hispanoamericanos de la década de 1820 -, se basó precisamente en una condición no igualitaria de la representación política: los representantes electos debían sobresalir de la mayoría en cuanto a riqueza, talento, instrucción y virtud. Para lograr elegir a los más virtuosos, el sistema debía garantizar que los representantes estuviesen claramente por encima de él, de esta manera, el Gobierno Representativo fue instituido con plena conciencia de que los representantes electos serían ciudadanos distinguidos por razones económicas, sociales, políticas y/o culturales. En ese sentido, esta idea de distinción se fundamentó en dos principios básicos: el primero, en la importancia de garantizar que los representantes mantuvieran una independencia económica; y el segundo, que su prestigio permitiera la búsqueda del bien general de la sociedad y no de intereses particulares.

\section{Declaración de Angostura, ¿Segunda independencia de Vene- ZUELA?}

Durante los días en que se realizó la convocatoria al Congreso se comentó en la capital de la República sobre las últimas noticias provenientes del viejo continente; al parecer, el gobierno español se encontraba en la búsqueda de apoyo de las monarquías europeas para retomar el control de sus posesiones americanas. En respuesta a estas alarmantes noticias, en el Correo del Orinoco se publicaron dos interesantes artículos donde se destacó la actuación de Venezuela y Nueva Granada desde el principio de la guerra para conseguir la independencia de un modo pacífico y amistoso y con la firme intención de mantener la República libre y soberana ${ }^{30}$.

30 Los artículos "La mediación" y "Continuación de la exposición sobre la mediación entre España y América", fueron publicados en Angostura en el Correo del Orinoco, n' 13, 17 de octubre de 1818; $\mathrm{n}^{\circ} 15,21$ de noviembre de $1818 ; \mathrm{n}^{\circ} 17,6$ de febrero de $1819 ; \mathrm{n}^{\circ} 18,13$ de febrero de $1819 ; \mathrm{y} \mathrm{n}^{\circ} 19$, 20 de febrero de 1819 . 
Por su parte, Simón Bolívar como jefe supremo de Venezuela realizó la denominada Declaración de Angostura el 20 de noviembre de 1818, misma que podría ser considerada como la segunda declaración de independencia. Previa convocatoria, se reunieron bajo la figura de Junta Nacional las principales autoridades civiles y militares del Gobierno y declararon "que la República de Venezuela por derecho divino y humano está emancipada de la nación española y constituida en un Estado independiente, libre y soberano" y que la única manera en que trataría con España sería de "igual a igual, en paz y en guerra, como lo hacen recíprocamente todas las naciones". De esta manera, ratificaron la declaración de independencia absoluta del 5 de julio de 1811 y sin vacilar revalidaron la guerra como mecanismo legítimo para alcanzar su objetivo más preciado: la libertad ${ }^{31}$. La declaración tenía como propósito revestir de legitimidad el establecimiento de la nueva República, de consolidar la representación nacional en el Congreso convocado y de desconocer la intervención de las potencias europeas en el afán de la monarquía española de reconquista de los antiguos territorios americanos.

\section{ENTRE LA ACEPTACiÓN Y EL RECHAZO}

Los últimos acontecimientos ocurridos en Angostura no tardaron mucho tiempo en llegar a la capital de la Capitanía General de Venezuela. Inmediatamente, las autoridades monárquicas caraqueñas condenaron, menospreciaron y ridiculizaron la proclama, convocatoria y reglamento electoral al segundo Congreso de Venezuela. La intención de los funcionarios realistas era disminuir la impresión favorable que podía producir en favor de la causa independentista a nivel local e internacional el establecimiento de un gobierno popular y representativo en la nueva república. Con este objetivo, el editor de la Gaceta de Caracas -semanario oficial del gobierno español en Venezuela-, el caraqueño José Domingo Díaz publicó el 30 de diciembre de 1818 una sátira que tituló AVISO IMPORTANTE, donde puso de manifiesto por medio de la ridiculización, la farsa y la ironía, lo que en su opinión significaron los vicios, locuras, abusos y deficiencias de

31 "Declaración de la República de Venezuela", Correo del Orinoco, Angostura, no 16, 30 de enero de 1819. 
la convocatoria al Congreso. Como veremos, utilizó la parodia, la burla, la exageración y las comparaciones como recurso literario al momento de descalificar las últimas noticias del gobierno republicano.

En el artículo Díaz hizo referencia a la convocatoria realizada por Simón Bolívar y a su capacidad de atender diferentes funciones: "Nosotros penetrados de la importancia y justicia de esta medida, y de que puede tener malas resultas tanto Simón: Simón de legislador, Simón de juez, Simón de dictador: Simón por delante y por detrás: Simón por arriba y por abajo: vuelta Simón y terna Simón”. Luego continuó reseñando las supuestas elecciones que se realizaron en los territorios monárquicos para la elección de diputados, las cuales calificó de "canónicas, y, lo más extraño en tales escenas, tranquilas y pacíficas”. Según los resultados, el Poder Ejecutivo sería ejercido por unanimidad de votos por Pablo Morillo, quien se desempeñaba como comandante del Ejército Expedicionario de Costa Firme y capitán general de Venezuela desde 1815. ${ }^{32}$

Como diputados "en el tantas veces convocado Congreso" se eligieron al brigadier Francisco Tomás Morales como representante de los Llanos de Caracas; a los coroneles Antonio Tovar y Juan Tello por Barinas; al mariscal de campo Miguel de la Torre por Caracas; por Valencia, San Carlos, Barquisimeto y San Felipe al brigadier Pascual Real y al teniente coronel Antonio Gómez; por Carora y Siquisiqui al coronel Juan de los Reyes Vagas; por Barcelona al teniente coronel Eugenio Arana; por Cumaná al teniente coronel Luis Genaro de la Roque; y "para otros partidos otras personas cuyos nombres no me acuerdo"33. En tono de burla e ironía, el editor de la Gaceta caraqueña nombró como parlamentarios a los principales oficiales del Ejército realista que se encontraban en todos los frentes de batalla contra las tropas republicanas para ese momento, principalmente los concentrados en la Campaña de Apure $e^{34}$. El artículo continuó ridiculi-

32 “AVISO IMPORTANTE”, Gaceta de Caracas, Caracas, n 227, 30 de diciembre de 1818. Negritas añadidas.

33 "AVISO IMPORTANTE", Gaceta de Caracas, Caracas, n 227, 30 de diciembre de 1818.

34 Campaña de Apure (1818-1819). Estas acciones fueron la respuesta a la ofensiva realista sobre el Apure, lanzada con el propósito de apoderarse de la zona y destruir las fuerzas del general José Antonio Páez. 
zando las elecciones republicanas en lo que se refería a las características de los electores, de los diputados, de la concurrencia y de otros aspectos relativos al proceso comicial:

\section{"Estamos ciertos de que la concurrencia será inmensa, y de que jamás en Venezuela se habrá visto una función ni tan circunspecta, ni tan magnífica: lo primero, porque no he- mos permitido que concurran a ella ni muchos ni mujeres; y lo segundo, así por el exterior de aseo y aun de lujo, que pre- sentarán las numerosas y diferentes comitivas de nuestros elegidos, como por el estruendo y armonía de las salvas y de las músicas". ${ }^{35}$}

En opinión de José Domingo Díaz, a pesar del entusiasmo manifestado por los republicanos, era cuestión de tiempo para que arribaran a Angostura los comandantes del Ejército realista: "mucho me temo que se deshaga la honorable corporación, y que con la llegada de nuestros electores se termine a mojicones, porque hay entre ellos hombres de malísimo genio", y que a la menor provocación o contradicción en sus opiniones "ni Juan Germán] Roscio le darán tripas, ni a [Francisco Antonio] Zea cara en que persignarse, ni a otros muchos cabeza que rascar". El mensaje era claro: intimidar con una posible acción militar sobre la capital de la república y la consecuente represión cruenta sobre los insurgentes como un recuerdo a los años más sanguinarios de la guerra a muerte.

Detrás de la sátira del artículo reseñado, su autor registró los fundamentos elementales del gobierno realista -mismos que serían ampliados en posteriores artículos y proclamas publicados en la Gaceta de Caracas- con el propósito de condenar, desconocer y menospreciar la convocatoria, reglamento y proceso comicial para el Congreso de Angostura de 1819. Entre los argumentos podrían destacar los siguientes: primero, se cuestionó la legitimidad del gobierno republicano para convocar a una Asamblea en representación del pueblo de Venezuela, cuando en realidad la mayor parte de

35 “AVISO IMPORTANTE”, Gaceta de Caracas, Caracas, n 227, 30 de diciembre de 1818. Negritas añadidas. 
las provincias que conformaban la Capitanía General se encontraba bajo el control del gobierno monárquico sin alteraciones significativas en los últimos años como consecuencia de la guerra de independencia; y segundo, la representatividad que tenía la misma, cuando solo podían realizar elecciones en una parte poco significativa del territorio venezolano. Quiero destacar que entre los alegatos de Díaz para desacreditar las últimas medidas del gobierno republicano instalado en Angostura, se encontraban también el fracaso de las pasadas experiencias representativas y el desarrollo de la guerra de independencia en los diferentes frentes militares que en su opinión, eran favorables para los ejércitos reales.

\section{Proceso electoral, 1819}

Los comicios para el segundo Congreso de Venezuela se realizaron en las regiones e instalaciones militares como estaba contemplado en el reglamento electoral de 1818 a pesar de algunos inconvenientes que se presentaron, a saber: las difíciles condiciones de la guerra de independencia que limitaron no solo el ejercicio ciudadano, sino que también representaron una permanente amenaza en las regiones limítrofes; las largas distancias que se tenían que recorrer para llegar a los centros de votación; y el hecho de que buena parte de los diputados seleccionados se encontraba en el frente de batalla o asumiendo responsabilidades gubernamentales en la capital de la novel República.

En las últimas semanas de 1818 no se tenían noticias de la realización del proceso electoral y ante la necesidad de instalar lo más rápido posible la Asamblea, las autoridades del Consejo de Estado enviaron una comunicación el $1^{\circ}$ de enero de 1819 a todas las autoridades políticas y militares instando a su realización. Esta urgencia evidencia dos puntos que debemos considerar: primero, las expectativas que existían por el establecimiento de un gobierno representativo que diera legitimidad a la República de Venezuela en el contexto local e internacional; y segundo, el temor al fracaso como consecuencia de las experiencias representativas del pasado.

Por cuestiones de distancia, el primero en responder fue el general Santiago Mariño el 4 de enero de 1819 desde su cuartel general instalado en 
El Pao, población cercana a Angostura perteneciente a la Provincia de Barcelona donde se encontraba en campaña militar. En la comunicación informó que la orden para el nombramiento de diputados "llegó a mis manos desgraciadamente en los momentos de mi marcha a esta provincia", pero a pesar de las dificultades y considerando "lo angustiado del tiempo" y además "penetrado de la importancia de la instalación del Congreso" realizó la votación preliminar en la división militar que lo acompañaba siendo seleccionados por unanimidad Francisco Antonio Zea, Diego de Vallenilla y los generales Tomás Montilla, Rafael Guevara y Rafael Urdaneta. También informó que las votaciones se sumarían a los resultados electorales de los otros cuerpos militares "y la de los pueblos" y para tal fin comisionó al general Andrés Rojas, comandante general interino de la división de Cumaná ${ }^{36}$. Los comicios realizados en plena campaña militar como en el caso reseñado-, se caracterizaron tanto por la desorganización como por el desconocimiento de la normativa electoral redactada para tal fin; seguramente las complejas condiciones de la guerra imposibilitaron que estas se realizaran de otra manera. Estas irregularidades fueron una constante en los espacios militares de participación política durante este y otros procesos electorales y donde todo parece indicar que lo importante era realizar los nombramientos a como diera lugar, caso contrario a lo ocurrido en los espacios civiles donde se procuró que los comicios se efectuaran conforme al derecho electoral.

La primera etapa del proceso para la elección de diputados al segundo Congreso de Venezuela correspondiente a la Provincia de Cumaná se realizó en la ciudad de Maturín el 24 de enero de 1819. Como lo estableció el reglamento, los comicios fueron organizados por la municipalidad reunida en Junta Nacional presidida por el general Andrés Rojas y con la participación de sufragantes de los pueblos de San Lorenzo, San Fernando, Arenas,

36 "Comunicación del general Santiago Mariño al consejo de gobierno", Sección venezolana del Archivo de la Gran Colombia, c. xxv, ff. 386-441, en Las Fuerzas Armadas de Venezuela en el siglo XIX [Textos para su estudio], comp. Pedro Grases y Manuel Pérez Vila (Caracas: Presidencia de la República, 1963) v. III, 11-12. El expediente original se titula "Listas de los ciudadanos y militares con derecho de sufragio que votaron por los diputados de la división de Maturín, Cumaná y Cumanacoa, para la formación del segundo Congreso de Venezuela", se encuentra en el Archivo General de la Nación de Colombia (AGNC), Sección Archivo Anexo, Fondo Historia, doc. 25, ff. 234-289. 
Acarigua, San Antonio, San Francisco y Guanagua, comunidades que pertenecían al departamento, así como también con la participación "de los individuos militares con derecho de sufragio". Luego de un breve discurso del general Rojas, según el acta del día "análogo a las circunstancias", se procedió a la elección procurando el mejor acierto ${ }^{37}$.

En el proceso participaron un total de 687 electores pertenecientes a los departamentos de Maturín (362 electores) y Cumanacoa (325 electores); los resultados se copiaron en los cuadernos electorales que incluían tres casillas por cada sufragante: en la primera se especificó la clase, es decir, grado militar, función política o ejercicio profesional; en la segunda, nombre y apellido del ciudadano elector; y en la tercera, los nombres de los candidatos para diputados de su preferencia ${ }^{38}$.

Por falta de información fidedigna, me fue imposible determinar con exactitud la población de la Provincia de Cumaná; sin embargo, luego de analizar diferentes referencias documentales podría sugerir que la participación ciudadana en este proceso electoral fue cercana al $20 \%$, cifra nada despreciable para unos comicios de estas características, aunque tendríamos que considerar que parte de los electores pertenecían al Ejército Libertador y no necesariamente eran oriundos de esta región del oriente venezolano.

Las preferencias electorales reflejaron un número importante de candidatos al contabilizar 96 personas que obtuvieron al menos un voto, aunque 12 de los seleccionados más votados reunían el $77 \%$ de los votos totales (3.435) y los 85 restantes representaban apenas el $23 \%$ (782). Si bien no existieron candidaturas formales, la ciudadanía de la Provincia de Cumaná seleccionó a destacados personajes políticos y militares oriundos en su mayoría del oriente venezolano, evidencia de un claro reflejo de la cultura política que se experimentó en este contexto electoral. Con respecto a la relación del voto civil y militar, vale la pena destacar que de las 96 candi-

37 "Votaciones", Sección venezolana del Archivo de la Gran Colombia, c. xxv, ff. 386-441, en Las Fuerzas Armadas..., v. III, 12 y ss.

38 "Lista de los sufragantes que han votado en los diputados que pertenecen a la división de Cumaná", Sección venezolana del Archivo de la Gran Colombia, c. xxv, ff. 386-441, en Las Fuerzas Armadas..., v. III, 13-14. 
daturas que al menos consiguieron un voto, 65 de ellos (65,59\%) eran militares y apenas 31 civiles $(34,41 \%)$. En el Cuadro 1 muestro información detallada de los resultados electorales de los 12 candidatos más votados en la Provincia de Cumaná y de los 84 aspirantes restantes ${ }^{39}$.

Cuadro 1. Personajes más votados en la Provincia de Cumaná para el II Congreso de Venezuela

\begin{tabular}{|l|c|c|}
\hline \multicolumn{1}{|c|}{ Nombre } & Votos & Preferencia \\
\hline Juan Martínez (doctor) & 463 & $67,3 \%$ \\
\hline Antonio José de Sucre (coronel) & 355 & $51,6 \%$ \\
\hline Rafael de Guevara (general) & 281 & $40,9 \%$ \\
\hline Santiago Mariño (general) & 276 & $40,1 \%$ \\
\hline Juan Germán Roscio (doctor) & 242 & $35,2 \%$ \\
\hline José Francisco Bermúdez (general) & 235 & $34,2 \%$ \\
\hline Tomás Montilla (general) & 180 & $26,2 \%$ \\
\hline Francisco Conde (coronel) & 157 & $22,8 \%$ \\
\hline Diego Vallenilla & 137 & $19,9 \%$ \\
\hline Francisco Antonio Zea (doctor) & 113 & $16,4 \%$ \\
\hline Rafael Urdaneta (general) & 111 & $16,1 \%$ \\
\hline Francisco Javier Mayz (coronel) & 102 & $14,8 \%$ \\
\hline Total de los más votados & 2652 & $77,2 \%$ \\
\hline Total menos votados (84 personas) & 782 & $22,8 \%$ \\
\hline Totales & 3435 & $100 \%$ \\
\hline
\end{tabular}

Fuente: Cuadernos Electorales. "Escrutinio", Sección venezolana del Archivo de la Gran Colombia, c. xxv, ff. 386-441, en Las Fuerzas Armadas..., v. III, 14-16.

El escrutinio definitivo se realizó en la ciudad de Maturín el 2 de febrero de 1819 en la casa del general Andrés Rojas con la presencia de las autoridades militares, civiles y religiosas de la provincia. Como presenté en el Cuadro 1 los doctores Juan Martínez y Juan Germán Roscio, el coronel Antonio José de Sucre y los generales Rafael de Guevara y Santiago Mariño fueron los cinco seleccionados para representar la provincia de Cumaná, mientras que como suplentes fueron elegidos los generales José Francisco Bermúdez y Tomás Montilla, el coronel Francisco Conde, Die-

39 Los datos que permitieron la elaboración del Cuadro 1 fueron tomados de los resultados que se encuentran en los cuadernos electorales. "Escrutinio", Sección venezolana del Archivo de la Gran Colombia, c. xxv, ff. 386-441, en Las Fuerzas Armadas..., v. III, 14-16. 
go Vallenilla y el doctor Francisco Antonio Zea ${ }^{40}$. En la comunicación que envió el general Rojas al consejo de gobierno advirtió que de los diputados electos solo se encontraba en ese momento el general Guevara, quien además "ha expuesto mil inconvenientes que le impiden su marcha en estos momentos”. Comisionó al sargento mayor José María España para que llevara directamente a la capital los documentos de los comicios realizados ${ }^{41}$.

Pocos días después de concluido el proceso electoral reseñado, nuevamente la preocupación gubernamental se hizo presente en el Correo del Orinoco, donde se comunicó al público en general las limitaciones y problemas ocurridos en las elecciones para el segundo Congreso venezolano: "distancias, dificultad en algunas comunicaciones, y movimiento de tropas". La prioridad del gobierno republicano era la rápida instalación de la Asamblea que para ese momento tenía más de dos meses de retraso. Hasta ese fin de semana solo habían llegado a Angostura los diputados de la Provincia de Barcelona, proceso que se realizó bajo la supervisión del general José Tadeo Monagas; los diputados electos por esta provincia fueron Diego Antonio Alcalá, los doctores Diego Bautista Urbaneja y Ramón García Cádiz y los coroneles Francisco Parejo y Eduardo Hurtado ${ }^{42}$.

La prensa se convirtió en una herramienta fundamental en la definición de la importancia y trascendencia del sufragio. Además de incorporar artículos que reflexionaban sobre las ventajas del sistema representativo, estas publicaciones periódicas -como el Correo del Orinoco- ofrecieron al público información detallada de las elecciones realizadas, inconvenientes, resultados obtenidos, entre otros aspectos que dan cuenta de la jornada comicial. A pesar de las escasas referencias sobre el particular, existieron otros medios de propaganda para difundir las convocatorias y resultados electorales: los papeles públicos colocados en lugares representativos de los pueblos y ciudades, o el aviso difundido por las autoridades civiles, militares y eclesiásticas casa por casa en la búsqueda de una mayor participación de la ciudadanía en estos eventos.

40 "Escrutinio", Sección venezolana del Archivo de la Gran Colombia, c. xxv, ff. 386-441, en Las Fuerzas Armadas..., v. III, 14-16.

41 “Comunicación del general Andrés Rojas", Sección venezolana del Archivo de la Gran Colombia, c. xxv, ff. 386-441, en Las Fuerzas Armadas..., v. III, p. 17.

42 Correo del Orinoco, Angostura, no 17, 6 de febrero de 1819. 
En edición $\mathrm{n}^{\circ} 17$ del Correo del Orinoco correspondiente al 6 de febrero de 1819, se informó la realización de las elecciones correspondientes a la Provincia de Caracas al mando del general Pedro Zaraza, donde fueron seleccionados como diputados los abogados José María España, Luis Tomás Peraza y Juan Germán Roscio, el científico y periodista neogranadino Francisco Antonio Zea y Onofre Basalo. A la par, se anunciaron los resultados electorales de la Provincia de Guayana: el general Pedro León Torres, Eusebio Afanador, Juan Vicente Cardozo y Fernando Peñalver. El reporte de los resultados electorales concluyó insistiendo en las limitaciones para su realización, pero "de hora en hora esperamos la venida de los ausentes; y luego que tengamos el número suficiente, comenzará sus funciones el Cuerpo Representativo de la Nación"43.

Unas semanas más tarde en el mismo semanario se dio a conocer la lista de los últimos diputados electos que integrarían el segundo congreso venezolano. Además de los representantes de las provincias de Cumaná, Barcelona, Caracas y Guayana mencionados anteriormente, se incorporarían a las actividades de la Asamblea por la Provincia de Barinas: los doctores Nicolás Pumas, Ramón Ignacio Méndez y Antonio María Briceño, el coronel Miguel Guerrero y el general Rafael Urdaneta. Por su parte, la Provincia de Margarita quedó representada por Gaspar Marcano, Domingo Alzúru, Manuel Palacios y José de Jesús Guevara. Todos los diputados hasta ahora mencionados se encontraban para ese momento en Angostura a la espera de los otros representantes. Para la edición del día 27 de febrero de 1819 del Correo del Orinoco, no se tenía información de los faltantes: "vendrán los de las Provincias de Casanare, y tres que faltan de los nombrados en Cumaná, Guayana y Margarita"44.

Las elecciones de la Provincia de Casanare -antiguo territorio perteneciente al Virreinato de Nueva Granada- evidenciaron algunos de los problemas que se presentaron en la realización de estos comicios para el congreso de Angostura, tales como los inconvenientes relacionados con las limitaciones en las comunicaciones, las largas distancias, la falta de diputa-

44 Correo del Orinoco, Angostura, nº 20, 27 de febrero de 1819. 
dos por encontrarse en actividades gubernamentales o militares, las dudas que suscitó la aplicación de la legislación electoral, entre otros aspectos que desarrollaré más adelante. El Correo del Orinoco en su edición del 24 de julio de 1819 -para ese momento ya habían transcurrido más de cinco meses de instalado el congreso-, participó a sus lectores que apenas el 11 de dicho mes habían llegado a la capital los resultados de las elecciones de la Provincia de Casanare. Entre las razones de este dilatado retraso se destacaron los problemas de comunicación de la provincia con Angostura -en términos actuales más de 1.200 kilómetros de distancia, aunque buena parte del trayecto se realizaba por vías fluviales-, y las dudas que suscitó el nombramiento de Francisco Antonio Zea como su diputado cuando ya había sido electo previamente como representante de la Provincia de Caracas. La normativa era clara en ese sentido y así lo reseñó el semanario oficial: "por el mismo hecho quedó representando a Casanare por el Sr. Zea [...] y dejó de serlo por la Provincia de Caracas"45.

El escrutinio final para el nombramiento de los diputados de Casanare se realizó el 29 de marzo de 1819 en la casa del general Francisco de Paula Santander ubicada en la población de Pore, bajo la supervisión de una comisión integrada por el coronel Jacinto Lara, los tenientes coroneles Pedro Fortoul, Joseph María Cancino, Antonio Obando y Vicente González, los capitanes Ramón García Guerra, Vicente Almeida e Ignacio Bartolomé Ruiz, los presbíteros Domingo A. Vargas y Luis Nepomuceno Uribe, curas del pueblo y el doctor Francisco Soto ${ }^{46}$.

Cuando se examinó la documentación de la jornada electoral se presentó una situación irregular en las actas de los pueblos de reducciones o misiones del Meta, al sur del territorio, comunidades mayoritariamente indígenas disgregadas entre las cuencas de los ríos Meta y Orinoco. En opinión

45 Correo del Orinoco, Angostura, no 34, 24 de julio de 1819. En referencia a la normativa: "Si resultare nombrado un mismo diputado por algunas muchas provincias y divisiones, lo será de la más distante". "Reglamento para la segunda convocatoria...", Correo del Orinoco, Angostura, No 14, 24 de octubre de 1818 y N $\mathrm{N}^{\circ} 15,21$ de noviembre de 1818.

46 "Decreto y acta de la comisión electoral presidida por el general Francisco de Paula de Santander en el cual se llevó a cabo la elección de los representantes y suplentes de la Provincia de Casanare para el Congreso General de Venezuela", AGNC, Sección Archivo Anexo, Fondo Historia, 25, doc. 63, ff. 544-546. 
de la comisión, en estas poblaciones se "habían incidido en defectos insanables, y que las constituían en abierta informalidad”, razón por la cual fue impugnado el proceso. Algunas de las irregularidades fueron: incapacidad del comisionado, escasa y dispersa población indígena apta para votar y la carestía de materiales para realizar el proceso. A pesar de la objeción, la comisión reconoció el derecho ciudadano de los indígenas del Meta "que siendo los individuos de las expresadas misiones, hábiles para votar, cuando más de la décima parte de los sufragantes de todas las provincias, los cuales ya habían votado legalmente" 47 .

Luego de una breve discusión donde se evaluaron los posibles inconvenientes que podría acarrear la repetición de las elecciones en el Meta, ya por las dificultades en las comunicaciones como consecuencia de las crecidas de los ríos de la región, como por el tiempo que llevaría realizarlas en esas condiciones -al menos un mes, en opinión de algunos miembros de la comisión-, el general Santander acotó la querella a dos puntos: la primera, ¿podrían prescindirse de estas elecciones? y en este caso, ¿sustancialmente podría modificar los resultados electorales provinciales?; y segundo, ¿ya se disponían de los Cuadernos Electorales suficientes de otras regiones para realizar el escrutinio final? De esta manera, la comisión resolvió prescindir de los resultados del Meta por presentar irregularidades y no consideraron su repetición "porque es demasiado pequeño el número de los que debían sufragar en ellas; y que era necesario se procediese a lo demás"48.

Sin contabilizar las poblaciones del Meta, participaron un total de 1.012 ciudadanos según el escrutinio. En el Cuadro 2 muestro los diez candidatos más populares - quienes aglutinaron más del $50 \%$ de los votos- obteniendo los tres primeros mayoría total de votos o absoluta, el resto fueron seleccionados con mayoría respectiva. Los primeros cinco fueron designados como diputados principales y el resto como suplentes. AGNC, Sección Archivo Anexo, Fondo Historia, 25, doc. 63, ff. 544-546. 
Cuadro 2. Personajes más votados en la Provincia de Casanare para el II Congreso de Venezuela

\begin{tabular}{|c|c|c|}
\hline Nombre & Votos & Preferencia \\
\hline Francisco Antonio Zea (doctor) & 796 & $78.6 \%$ \\
\hline José María Salazar (doctor) & 687 & $67.8 \%$ \\
\hline José María Vergara (coronel) & 604 & $59.6 \%$ \\
\hline Vicente Uribe (teniente coronel) & 557 & $55.1 \%$ \\
\hline Ignacio Mariño y Torres (coronel) $^{1}$ & 526 & $51.9 \%$ \\
\hline Antonio Morales (teniente coronel) & 496 & $49.1 \%$ \\
\hline Ignacio Muñoz (doctor) & 439 & $43.3 \%$ \\
\hline Francisco Escobar & 403 & $39.8 \%$ \\
\hline Francisco Javier Yánez (doctor) & 394 & $38.9 \%$ \\
\hline Domingo Antonio Vargas (presbítero) & 228 & $22.5 \%$ \\
\hline Total de votos & 5130 & $50.7 \%$ \\
\hline
\end{tabular}

Fuente: Cuadernos Electorales. "Escrutinio", Sección venezolana del Archivo de la Gran Colombia, c. xxv, ff. 386-441, en Las Fuerzas Armadas..., v. iii, 14-16.

En la sesión del Congreso de Angostura del 12 de julio de 1819 se incorporaron como diputados de la Provincia de Casanare el coronel José María Vergara y el teniente Vicente Uribe. El presidente de la Asamblea, el diputado Francisco Antonio Zea, destacó en su discurso la importancia de la unión entre Nueva Granada y Venezuela que se manifiesta en la incorporación de los representantes de esa región al Congreso venezolano: "acontecimiento en la historia que probaría el conocimiento que ambos países habían adquirido de sus verdaderos intereses y que los de la guerra había sido tales que produjeron el efecto deseado, uniendo de hecho a los habitantes de uno y otro territorio" ${ }^{49}$.

Ciertamente, la escasa documentación que perduró hasta nuestros días no fue suficiente para reconstruir a plenitud el proceso electoral del Congreso de 1819, aunque puedo afirmar que la muestra presentada refleja la compleja dinámica de los comicios en un escenario dominado por la guerra de independencia y sus secuelas, a la vez que muestra la cultura política de sus habitantes en esta época de transición. Una revisión más exhaustiva en archivos regionales y locales sobre el particular podría arrojar interesantes resultados a estos temas que la historiografía venezolana no ha prestado la suficiente atención. 


\section{REFLEXIÓN FINAL}

Superados los inconvenientes que se presentaron para la realización del proceso comicial del segundo Congreso de Venezuela, este se instaló el 15 de febrero de 1819 en la ciudad de Angostura, capital de la novel República, con la asistencia de 26 de los 30 representantes electos. Los avatares de la guerra de independencia, los desencuentros entre los líderes civiles y militares y la inestabilidad de las instituciones republicanas, no habían permitido la reunión exitosa de una Asamblea Legislativa desde el primer ensayo de gobierno representativo que se desarrolló en este territorio entre 1811 y 1812 .

Las provincias pertenecientes a la antigua Capitanía General de Venezuela que estuvieron representadas en la Asamblea fueron: Caracas, Barcelona, Cumaná, Barinas, Guayana y Margarita. Asimismo, en la búsqueda de una mayor participación, integración y por consiguiente, legitimidad política, se contempló la posibilidad de que pudiesen enviar diputados las provincias de Mérida, Trujillo y Casanare, esta última perteneciente a los territorios de la Nueva Granada, la única de esa región que para ese momento se encontraba libre de la ocupación militar española. La idea de Colombia era una posibilidad real que ya se estaba materializando.

En la instalación y desenvolvimiento de esta nueva institucionalidad republicana y representativa, no solamente se intentó desmantelar el sistema monárquico español dominante, sino que también se dieron avances importantes en la creación, construcción e implementación de una nueva cultura política amparada en el sistema representativo que le dio vida al fracaso más exitoso de los libertadores de Tierra Firme, popularmente conocida como la Gran Colombia. Es importante recordar que fue precisamente en esta Asamblea donde se promulgó el 17 de diciembre de 1819 la Ley Fundamental de la República de Colombia que consagró la unión de Venezuela, Nueva Granada y Quito. Este acuerdo sería ratificado en el primer Congreso General de la República de Colombia que se reunió en la Villa del Rosario de Cúcuta a principios de 1821; la elección de sus representantes fue normada y organizada por el mismo Congreso venezolano de 1819.

Esa experiencia no tuvo como resultado la consolidación de la Nación decretada en Angostura, ya que se disolvió una década más tarde entre 1830 
y 1831. A pesar de todo, sí cumplió con el principal objetivo político y militar de sus creadores: lograr la independencia absoluta de estos territorios. Pero un aspecto que considero fundamental destacar, es que durante esos difíciles años de convivencia se sostuvo y practicó el principio de la representación como fundamento de la legitimación política, creando y consolidando una cultura política moderna que no desapareció con la disolución de la unidad colombiana, sino que por el contrario, se mantuvo, extendió y enriqueció en los procesos de construcción y consolidación de las repúblicas que nacieron con su disolución: Venezuela, Ecuador y Nueva Granada, esta última retomaría el nombre de Colombia años más tarde.

\section{Bibliografía}

\section{Fuentes primarias}

\section{Archivo}

Archivo General de la Nación de Colombia (AGNC), Bogotá. Sección Archivo Anexo, Fondo Historia, Doc. 25.

\section{Publicaciones periódicas}

Correo del Orinoco, Angostura, 1818-1822.

Gaceta de Caracas, Caracas, 1808-1822.

\section{Fuentes secundarias}

Annino, Antonio (coord.). Historia de las elecciones en Iberoamérica, siglo XIX. De la formación del espacio político nacional. México: Fondo de Cultura Económica, 1955.

Ávila, Alfredo. En nombre de la nación: la formación del gobierno representativo en México. México: Universidad Nacional Autónoma de México, 2005.

Bushnell, David. "La evolución del derecho de sufragio en Venezuela". Boletín Histórico No 29, mayo (1972): 195.

Guía, Germán. "El voto militar de 1819: instituido durante las vicisitudes de la guerra de independencia". CONHISREMI, Revista Universitaria de Investigación y Diálogo Académico, Vol. 4, No 1 (2008): 195.

Hébrard, Véronique. “¿Patricio o soldado: qué «uniforme» para el ciudadano? El hombre en armas en la construcción de la Nación (Venezuela, $1^{\text {ra }}$ mitad del siglo XIX)". Revista de Indias, $n^{\circ} 225$, mayo-agosto (2002): 441. 
Hébrard, Véronique. "Ciudadanía y participación política en Venezuela, 1810-1830". En Independence and Revolution in Spanish America: Perspectives and Problems, editado por Anthony McFarlane y Eduardo Posada-Carbó. Londres: University of London e Institute of Latin American Studies, 1999, 122-153.

Irwin G., Domingo. "El voto militar en Venezuela: una visión histórica de conjunto", Latin American Studies Association, (2004): s/p.

Las Fuerzas Armadas de Venezuela en el siglo XIX [Textos para su estudio], compilado por Pedro Grases y Manuel Pérez Vila. Caracas: Presidencia de la República, 1963.

Manin, Bernard. Los principios del gobierno representativo. Madrid: Alianza Editorial, 1998.

Pitkin, Hanna Fenichel. El concepto de representación. Madrid: Centro de Estudios Constitucionales, 1985.

Quintero, Inés y Almarza V., Ángel Rafael. "Una segunda oportunidad. Representación y revolución en la República de Colombia: 1819-1830”. En Las revoluciones en el largo XIX latinoamericano, editado por Rogelio Altez y Manuel Chust. Madrid: Iberoamericana/Vervuert, Estudios AHILA de Historia Latinoamericana, 12, 2015, 109-130.

Restrepo, José Manuel. Historia de la revolución de la República de Colombia en la América Meridional. Medellín: Editorial Universidad de Antioquia, 2009, $2 \mathrm{v}$.

Ternavasio, Marcela. La revolución del voto. Política y elecciones en Buenos Aires, 1810-1852. Buenos Aires: Siglo XXI, 2002.

Thibaud, Clément. "Formas de guerra y mutación del ejército durante la guerra de la independencia en Colombia y Venezuela". En Revolución, independencia y las nuevas naciones de América, coordinado por Jaime E. Rodríguez O. Madrid: Fundación MAPFRE Tavera, 2005, 358.

Thibaud, Clément. República en armas. Los ejércitos bolivarianos en la guerra de independencia en Colombia y Venezuela. Bogotá: Instituto Francés de Estudios Andinos y Editorial Planeta, 2003.

Para citar este artículo: Almarza Villalobos, Ángel Rafael. "El II Con114 greso de Venezuela. Conformación de un gobierno popular representativo, Angostura: 1818-1819", Historia Caribe Vol. XIII No. 32 (Enero-Junio 2018): 81-114. DOI: http://dx.doi.org/10.15648/hc.32.2018.4 